\title{
Avaliação da qualidade microbiológica e georreferenciamento de fontes hídricas utilizadas por moradores do município de Divinópolis
}

(MG)

No município de Divinópolis (MG), muitos moradores têm-se utilizado de fontes hídricas, cujas informaç̃es relativas à qualidade da água são inexistentes ou encontram-se desatualizadas. Tal prática intensificou-se nos últimos meses de 2014, sobretudo em virtude do déficit pluviométrico observado na última estação chuvosa, com consequente desabastecimento em alguns pontos da cidade. Dentro deste contexto, o presente trabalho visou avaliar a qualidade microbiológica e aspectos físico químicos de amostras de água coletadas em 4 nascentes localizadas no município de Divinópolis (MG), e frequentemente utilizadas por moradores de seu entorno para consumo próprio sem quaisquer tipos de tratamento prévio ao consumo. Em duas das fontes analisadas, foram constatadas condiç̃es inadequadas para o consumo da água e cujos dados fogem aos parâmetros microbiológicos de potabilidade definidos pela legislação vigente. Comprovou-se, ainda que a fervura trouxe bons resultados, sob o ponto de vista de redução de bactérias heterotróficas totais e eliminação do indicador microbiológico de contaminação fecal. Todas as fontes hídricas analisadas foram catalogadas e georreferenciadas e os dados disponibilizados em blog construído para tal. As informações levantadas foram repassadas à população por meio de reuniões com os moradores circunvizinhos às áreas estudadas, sendo o projeto considerado um piloto a ser desenvolvido em outras regiões da cidade.

Palavras-chave: Divinópolis (MG); SACs; Qualidade; Georreferenciamento.

\section{Evaluation of microbiological quality and georeferencing of water sources used by residents of Divinópolis (MG)}

In the municipality of Divinópolis (MG), many residents have been using water sources, whose information on water quality is non-existent or outdated. This practice intensified in the last months of 2014, mainly due to the rainfall deficit observed in the last rainy season, with consequent shortage in some parts of the city. Within this context, the present work aimed to evaluate the microbiological quality and physicochemical aspects of water samples collected in 4 springs located in the municipality of Divinópolis (MG), and frequently used by residents of their surroundings for their own consumption without any previous treatment. to consumption. In two of the sources analyzed, inadequate conditions for water consumption were found and their data are outside the microbiological parameters of potability defined by current legislation. It was also proved that boiling had good results from the point of view of reducing total heterotrophic bacteria and eliminating the microbiological indicator of fecal contamination. All water sources analyzed were cataloged and georeferenced and the data available in a blog built for such. The information collected was passed on to the population through meetings with the surrounding residents to the studied areas, and the project was considered a pilot to be developed in other regions of the city.

Keywords: Divinópolis (MG); SACs; Quality; Georeferencing.

Topic: Microbiologia Agrícola e Ambiental

Reviewed anonymously in the process of blind peer
Received: 09/01/2019

Approved: 09/02/2019
Adriano Guimaraes Parreira (iD)

Universidade Federal de São João Del-Rei, Brasil

http://lattes.cnpq.br/1803178442452988

http://orcid.org/0000-0002-7770-7165

aguiparreira@ufsj.edu.br

\section{Fabricio Máximo Orlando}

Universidade Federal de São João Del-Rei, Brasil

aguiparreira@yahoo.com.br

Camila Castro Mourão

Universidade Federal do Rio Grande, Brasi

http://lattes.cnpq.br/2299444091191678

aguimaparreira@gmail.com

DOI: 10.6008/CBPC2237-9290.2019.001.0002
Referencing this:

PEREIRA, A. G.; ORLANDO, F. M.; MOURÃO, C. C.. Avaliação da qualidade microbiológica e georreferenciamento de fontes hídricas utilizadas por moradores do município de Divinópolis (MG). Natural Resources, v.9, n.1, p.11-19, 2019. DOI: http://doi.org/10.6008/CBPC2237-9290.2019.001.0002 


\section{INTRODUÇÃO}

A água é elemento essencial à vida de todo ser humano, e o acesso a uma fonte segura e suficiente de água potável é requisito fundamental para a sobrevivência, bem-estar e desenvolvimento socioeconômico de toda comunidade (BECHARA, 1992). A abundância de água no planeta causa a falsa sensação de um recurso natural inesgotável, o que pode conduzir a ações inconsequentes e irreversíveis, gerando cada vez mais desperdício e escassez. Cobrindo aproximadamente $3 / 4$ da superfície do planeta, a maior parte da água, $94,7 \%$, é salgada e encontra-se nos oceanos; $1,8 \%$ está congelada nas regiões polares e apenas o restante, $0,8 \%$, é doce e está disponível para o consumo da população mundial, não se conhecendo exatamente a fração correspondente que se encontra contaminada ou em boas condições de uso (REBOUÇAS et al., 1999; LIMA, 1999).

Em relação às águas superficiais, o Brasil detém 13,7\% do total da água doce do planeta, embora mais de 73\% encontram-se disponíveis na bacia Amazônica, habitada por menos que 5\% da população total do país. Por outro lado, apenas $27 \%$ dos recursos hídricos superficiais brasileiros estão disponíveis para as demais regiões, onde residem aproximadamente $95 \%$ da população brasileira. Portanto, mesmo dispondo de recurso hídrico abundante, em virtude de sua má distribuição e ainda má utilização, o Brasil não está livre da ameaça de uma crise de desabastecimento, sobretudo nos grandes centros urbanos, o que já vem sendo sentido pela população de algumas metrópoles do país nos últimos três anos, principalmente.

O país vem sofrendo a cada ano com o aumento da escassez de água doce de boa qualidade devido, sobretudo a ações inconsequentes e irreversíveis relacionadas ao rápido e desordenado crescimento populacional e industrial, associado a formas de uso irracionais, somado ao déficit hídrico registrado nas últimas estações chuvosas em várias regiões do território brasileiro.

No que se refere à qualidade das fontes hídricas, a água pode atuar como importante veículo de propagação de uma série de doenças e, quando contaminada, pode acarretar sérios prejuízos à saúde da população, sobretudo crianças e idosos (SAUNDERS et al., 1983). Pode atuar como veículo de transmissão da cólera, febre tifoide e hepatite, colocando em risco inúmeras pessoas que podem vir a óbito a depender da concentração e cepas de patógenos envolvidos.

Ainda que sujeito a controvérsias, antes de 1900 já se associava a ocorrência de doenças com a água. Desde a década de 1840, havia referências de que as epidemias de febre tifoide e de cólera em Londres estavam relacionadas com águas de qualidade duvidosa. Estudos de John Snow, sobre epidemias anteriores, como a epidemia de cólera de 1854 que levou a óbito mais de 600 pessoas em menos de uma semana, foram decisivos para finalmente demonstrar a veiculação de doenças pela água.

Esse estudo culminou com a segunda publicação do livro de John Snow, On the Mode of Communication of Cholera, no qual são relatadas evidências da relação entre a contaminação hídrica com a transmissão da doença, sendo considerado o primeiro tratado de Epidemiologia conhecido. A partir daí, e com o advento da microbiologia, tendo Pasteur como pioneiro, ao propor em 1864 a Teoria Microbiana das Doenças (MWH, 2005), teve impulso o reconhecimento, em bases científicas, da associação entre a qualidade 
das águas, saúde pública e o desenvolvimento das técnicas de tratamento de água. Até o início do século XX, não havia padrões definidos de qualidade para a água potável.

Nos Estados Unidos, ainda na década de 1890, a United States Public Health Service (USPHS) propôs um esforço cooperativo para a padronização dos testes bacteriológicos, evoluindo para a primeira edição do Standard Methods for the Examination of Water and Wastewater. A fim de se avaliar a situação microbiológica da água destinada ao consumo humano é necessário um acompanhamento permanente com análises periódicas de sua condição, seja ela proveniente de minas, nascentes, rios, lagos ou oceanos, que podem variar a depender de diversos fatores, incluindo condições meteorológicas. As análises de água devem ser realizadas com regularidade e frequência, uma vez que poluição fecal é intermitente e poucas amostragens podem não ser suficientes para detectá-la.

A qualidade microbiológica da água pode ser determinada por análises bacteriológicas. Microrganismos patogênicos (Salmonella typhi, Vibrio cholerae, Shigella dysenteriae, vírus da hepatite, entre outros) podem ser isolados de águas contaminadas, usando-se procedimentos trabalhosos e demorados. É impraticável pesquisar rotineiramente todos os patógenos que possivelmente são veiculados pela água, dada sua concentração extremamente baixa, o que requer métodos específicos de concentração, e cuja aplicabilidade limita-se a eventos e ocasiões específicas, como no caso da ocorrência de surtos.

Assim, o controle microbiológico da qualidade da água é feito determinando-se a presença de microrganismos de origem fecal, cuja presença indica poluição da água por dejetos humanos ou de animais, indicando o risco da presença de microrganismos enteropatogênicos (GOMES, 1973). A água potável não deve conter microrganismos patogênicos e deve estar livre de bactérias indicadoras de contaminação fecal. Os indicadores de contaminação fecal, tradicionalmente aceitos, pertencem a um grupo de bactérias coliformes.

Os motivos da escolha desse grupo são fundamentalmente o de estarem presentes nas fezes de animais de sangue quente, inclusive de seres humanos. Sua presença na água possui uma relação direta com o grau de contaminação fecal: são facilmente detectáveis e quantificáveis por técnicas simples e economicamente viáveis; possuem maior tempo de vida na água que as bactérias patogênicas intestinais, são menos exigentes em termos nutricionais e incapazes de se multiplicarem no ambiente aquático, além de serem mais resistentes à ação dos agentes desinfetantes do que os germes patogênicos.

O grupo coliforme é definido pelas seguintes características: são bastonetes Gram negativos, não formadores de esporos, aeróbios ou anaeróbios facultativos, fermentam a lactose a $35-37^{\circ} \mathrm{C}$, produzindo ácido, gás e aldeído em um intervalo de 24-48 horas, sendo ainda oxidase-negativos. Trata-se de um grupo heterogêneo e representado pelos gêneros Escherichia, Enterobacter, Klebsiella e Citrobacter. O principal representante desse grupo de bactérias chama-se Escherichia coli.

O conceito de utilizar coliformes para deduzir a presença de patógenos baseou-se em trabalho realizado em 1885 pelo estudioso Escherich, através da identificação do Bacilo de coli como fazendo parte da microflora intestinal natural de animais de sangue quente. Além disso, E. coli indica contaminação fecal 
recente, sendo caracterizada também como termotolerante, ou seja, fermentam a lactose com produção de gás quando incubados a $44,5^{\circ} \mathrm{C}-45^{\circ} \mathrm{C}$ por 24 horas (MCKINNFY, 1963).

Água potável é aquela que pode ser consumida sem riscos à saúde e sem causar rejeição ao consumo, sendo que o monitoramento de sua qualidade é um dos instrumentos de verificação da potabilidade e de avaliação dos riscos que os sistemas e as soluções alternativas de abastecimento de água (SACs) possam representar para a saúde humana (BRASIL, 2006).

Em relação ao tratamento da água, um dos métodos mais antigos e eficazes é sua fervura. Porém, do ponto de vista prático, restrita a aplicação no âmbito das unidades residenciais. Em 1870, e durante alguns anos posteriores, o uso de filtros de areia e de outras técnicas de tratamento ainda visava melhorar o aspecto estético da água, eliminar o odor e melhorar o sabor. O avanço do conhecimento deu lugar ao tratamento da água com vistas à proteção à saúde, em virtude de eventos de contaminação por várias doenças por ela transmitidas, seja em decorrência de excretas humanas ou animais, seja pela presença de substâncias químicas nocivas à saúde do homem (TORTORA, 2005).

A avaliação microbiológica da água de minas, nascentes, rios, riachos, lagos, oceanos ou proveniente de toda fonte que, eventualmente possa vir a prejudicar o homem, necessita ser realizada periodicamente, com vistas a garantir a segurança necessária para a definição de sua aplicabilidade e o conhecimento das intervenções remediadoras que se fazem necessárias (GUILHERME, 2000).

Segundo dados apresentados pela ONU (Organização das Nações Unidas), anualmente morriam cerca de 1,8 milhões de pessoas em todo o mundo devido a diarreias associadas à má qualidade das águas, das quais 1,6 milhões são crianças menores de 5 anos (WHO, 2004). No Estado de Minas Gerais, relatório de monitoramento da qualidade das águas superficiais, apresentado pelo Instituto Mineiro de Gestão das Águas (IGAM), referente ao primeiro trimestre de 2011, deixa claro que os parâmetros que apresentaram o maior número de violações dentre as amostras analisadas, provenientes de diferentes Bacias Hidrográficas do estado, relacionavam-se a coliformes termotolerantes (85\%), seguindo-se de manganês total (55\%) e ferro dissolvido (47\%).

É importante ressaltar que se predominou na avaliação do Índice de Qualidade das Águas (IQA) a chamada água de qualidade média, correspondendo a $55 \%$ do total de amostras analisadas. As ocorrências de IQA Bom diminuíram de 25\% em 2010 para 7\% no mesmo período em 2011, e as ocorrências de IQA Ruim aumentaram de 21,5\% em 2010 para 37,6\% em 2011 (IGAM, 2011). Em Divinópolis (MG), é sabido que volumes de água provenientes de SACs, a exemplo de minas e nascentes, são utilizados para consumo por parte de alguns moradores, mesmo não recebendo quaisquer tipos de tratamentos e ausentes de informações seguras, periódicas ou atualizadas, referentes à sua qualidade, o que representa um sério risco a saúde pública e um precioso recurso em potencial a ser melhor explorado. Neste sentido, o presente trabalho avaliou a condição microbiológica e alguns aspectos físico-químicos de amostras de água coletadas em um total de 4 SACs, frequentemente utilizadas por moradores do município de Divinópolis (MG). 


\section{MATERIAIS E MÉTODOS}

Os experimentos foram executados no Laboratório de Microbiologia da UEMG - Unidade Divinópolis (MG). Amostras de água foram coletadas em período seco (meses de maio a julho de 2014) e período chuvoso (dezembro 2014 a fevereiro de 2015) em 4 nascentes utilizadas rotineiramente pela população circunvizinha, conhecidas como: CSU (Centro Social Urbano - Bairro Interlagos); Canto da Mina-própria (Bairro Niterói); Mina Bela Vista (Bairro Bela Vista); e Mina do Baiano (Bairro Belvedere).

No Canto da Mina há dois pontos de coleta diferentes, com placas indicativas colocadas pela Prefeitura Municipal alertando sobre qual seria o ponto de coleta contendo água própria e o ponto contendo água imprópria para consumo humano, sendo que este trabalho focou na fonte considerada própria ao consumo. As coletas das amostras foram realizadas em condições assépticas e empregados frascos esterilizados em autoclave $\left(121^{\circ} \mathrm{C}\right.$ por 20 minutos) ou por raios gama, seguindo-se os procedimentos de coleta descritos nos protocolos contidos no Manual Prático de Coleta de Água (FUNASA, 2009).

As análises microbiológicas seguiram os protocolos descritos em Standard Methods for the Examination of Water and Wastewater, 1985, e os valores encontrados comparados aos parâmetros definidos pela Portaria 2914/11 (BRASIL, 2011). Para a avaliação da presença de coliformes totais e E. coli foi adotada a técnica do substrato cromogênico, empregando-se para tal kit diagnóstico LKP.

Foram efetuadas duas coletas quinzenais, em cada ponto de amostragem, ao longo dos meses descritos anteriormente. A fim de se avaliar a densidade de bactérias heterotróficas, presentes nas amostras coletadas, foram executados plaqueamentos de alíquotas das mesmas em meio ágar-nutriente, seguindo-se de posterior incubação das placas em estufa a $30^{\circ} \mathrm{C}$ por $48 \mathrm{~h}$.

Em seguida, avaliou-se a diversidade microbiana a partir da observação macroscópica da morfologia e coloração das colônias presentes nas placas, sendo ainda levantados dados quantitativos a partir da contagem do total de colônias e os valores convertidos em UFC $\mathrm{mL}^{-1}$ com base nas diluições selecionadas para as contagens. $\mathrm{O}$ trabalho envolveu a participação de dois estudantes de escola pública do ensino médio, bolsistas BICJr, além do professor orientador. A figura 1 ilustra três das regiões onde foram coletadas amostras de água para a execução das análises laboratoriais (Mina Bela Vista, Mina do Baiano e Canto da Mina).
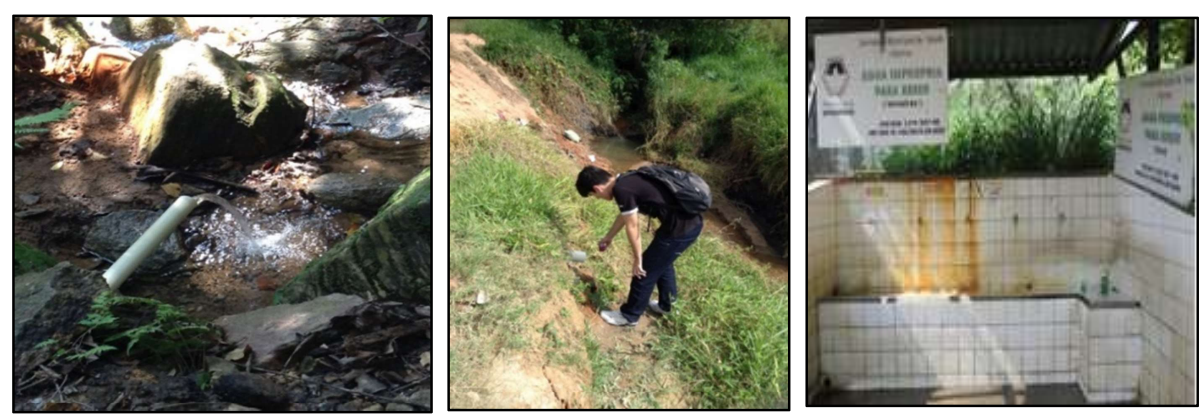

Figura 1: Locais utilizados pela população para coleta de água para consumo próprio, conhecidos como Mina Bela Vista, Mina do Baiano e Canto da Mina, respectivamente (esquerda para direita). 
Para a adoção de estratégias alternativas de descontaminação, amostras de água foram submetidas à fervura em micro-ondas por um período de 3 minutos, seguindo-se de plaqueamentos em meio ágarnutriente, posterior à incubação em estufa nas condições já descritas e avaliação da densidade microbiana, comparando-se o crescimento microbiano e número de colônias entre as placas cujas amostras de água foram submetidas previamente ao tratamento de fervura, e placas controle, cujas amostras de água não foram previamente aquecidas. Além disso, parâmetros físico-químicos das amostras também foram levantados, pH e turbidez, utilizando-se para tal pHmetro Metrohm ${ }^{\circ}$ e turbidímetro Hach ${ }^{\circ}$, respectivamente.

No que se refere ao georreferenciamento, foi utilizado GPS marca Garmin Trex Vista ${ }^{\circ} \mathrm{H}$, gentilmente cedido pela UEMG Unidade Divinópolis (MG). As coletas durante o período chuvoso foram realizadas conforme previsto, contudo, em virtude da redução excepcional de pluviosidade em todo o Sudeste brasileiro entre os meses finais de 2014 e início de 2015, os resultados que refletiram alterações típicas períodos de maior pluviosidade foram observados no mês de fevereiro de 2015.

\section{RESULTADOS E DISCUSSÃO}

Para a mina Bela Vista constatou-se ausência completa de contaminação por coliformes totais e $E$. coli, o mesmo ocorrendo para as amostras coletadas no Canto da Mina (próprio) para todas as amostras coletadas e para todos os períodos amostrados, ou seja, tanto para meses com maior quanto menor média de pluviosidade. Para as amostras coletadas na mina do Baiano e CSU, por sua vez, detectou-se contaminação tanto para coliformes totais quanto para E. coli, para a totalidade das amostras analisadas, com destaque para aquelas provenientes da mina do Baiano.

Além disso, o crescimento de heterotróficos totais, tanto em termos de diversidade quanto em quantidade foi visivelmente mais significativo nas placas inoculadas com amostras das minas do Baiano e CSU, comparativamente àquelas inoculadas com amostras provenientes das minas Bela Vista e Canto da Mina, conforme pode-se confirmar na figura 2. Neste particular, a contagem de colônias, após novos plaqueamentos e obtenção de culturas puras, revelou quantidades superiores a 3x o total de colônias obtidas para amostras provenientes das minas Bela Vista e Canto da Mina. Todos os testes realizados para amostras provenientes da Mina do Baiano e CSU apresentaram valores de heterotróficos totais que extrapolaram os limites toleráveis definidos na Portaria 2914/11.
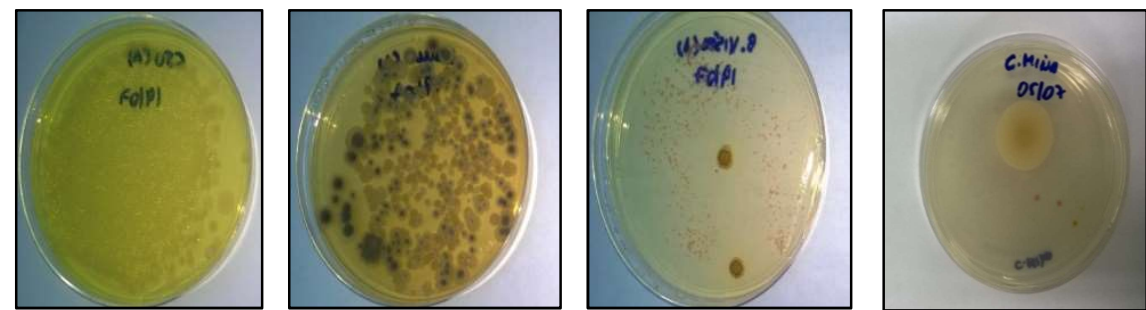

Figura 2: Crescimento de heterotróficos totais em placas contendo meio ágar-nutriente inoculadas com amostras de água provenientes da Mina do Baiano, CSU, Mina Bela Vista e Canto da Mina (esquerda para direita).

Após a execução dos procedimentos de fervura, previamente aos plaqueamentos, verificou-se redução de até $90 \%$ no número total de colônias crescidas nas placas, comparativamente ao obtido para 
placas-controle, com destaque para as amostras coletadas na Mina do Baiano e CSU para todas as amostragens realizadas. De fato, é consenso entre os estudiosos de que a fervura representa o método mais eficaz na destruição de microrganismos potencialmente patogênicos para o homem, tanto para bactérias quanto para protozoários, sobretudo em regiões ou sistemas desprovidos de tratamento adequado (MADEIRA, 2007).

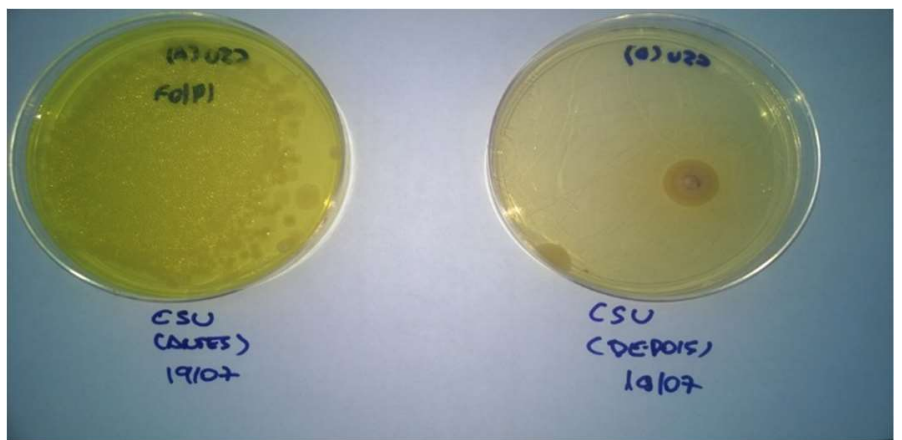

Figura 3: Efeito da fervura das amostras de água sobre o crescimento de heterotróficos totais em placas de petri contendo meio de cultura ágar-nutriente. Placas 1 e 2 representam o resultado de plaqueamentos de alíquotas de amostras de água coletadas no CSU, antes e após a fervura, respectivamente.

Em relação ao pH, a maioria das amostras aproximaram-se da neutralidade (Canto da Mina 6,9; CSU 6,3; Bela Vista 7,5) com exceção das amostras coletadas na mina do Baiano, com valor de pH próximo de 5,2. Em relação ao $\mathrm{pH}$ de amostras de água, ecossistemas que apresentam valores baixos de $\mathrm{pH}$ podem apresentar elevadas concentrações de ácidos orgânicos dissolvidos de origem alóctone ou autóctone. De acordo com Amaral (1988), o pH pode ser considerado uma das variáveis ambientais mais importantes e complexas de se interpretar, devido ao grande número de fatores envolvidos e que podem influenciá-lo. Podemos observar em nosso estudo que os valores de $\mathrm{pH}$ de todos os pontos, exceto a mina do Baiano, estão dentro das normas definidas na portaria 2914/11.

No que se refere à turbidez, amostras da mina do Baiano apresentaram os valores mais altos, ou seja, média de 3,4uT, quando comparados aos demais valores, obtidos para as minas Bela Vista (1,1uT); CSU (2,5uT) e Canto da Mina (1,3uT). Conforme os parâmetros estabelecidos na Portaria 2914/11, o valor máximo permitido para a turbidez é de 1,0uT em 95\% das amostras para águas de filtração lenta.

As minas do Baiano e Canto da Mina apresentaram, portanto, as maiores distorções neste quesito, o que indicaria a presença de sólidos em suspensão provenientes de rochas, argilas, silte, algas ou outros microrganismos, originados de despejos domésticos, industriais ou naturalmente de eventos de erosão. $A$ presença destes materiais suspensos apresenta como inconveniente direto a possibilidade de servirem de abrigo para microrganismos patogênicos, diminuindo a eficácia da desinfecção. Partículas maiores, por exemplo, podem servir de abrigo para bactérias, protegendo-as de agentes desinfetantes, sobretudo cloro (SPERLING, 2005).

No que tange ao georreferenciamento, após conversão dos dados, foram levantadas as seguintes coordenadas: Mina Bela Vista (Long.: -44.54.269, Lat.: -20.10.118); CSU (Long.: 44.52.558, Lat.: -20.09.300); Canto da Mina (Long.: 44.52.627, Lat.: -20.08.775); Baiano (Long.: 20.10.524, Lat.: -44.54.568), sendo que tais 
dados assumem especial importância para estudos futuros relacionados a avaliação da preservação ou manutenção daquelas fontes hídricas naqueles determinados locais.

Com base nos dados obtidos é notório que as amostras de água provenientes da Mina do Baiano e CSU não apresentam condições microbiológicas e nem aspectos físico-químicos ideais ou adequados para consumo humano, sobretudo para dessedentação sem tratamento prévio. Como alternativa de tratamento provou-se que a fervura reduziu sobremaneira a população bacteriana presente em todas as amostras, com destaque para as amostras coletadas na mina do Baiano, com redução aproximada de $90 \%$ do total inicialmente observado.

No que se refere ao $\mathrm{pH}$ e turbidez, novamente as amostras provenientes da mina do Baiano e CSU se distanciaram em maior amplitude dos parâmetros estabelecidos pela portaria 2914/11, devendo as análises serem novamente realizadas, sobretudo em relação ao pH. Em relação as minas do Bela Vista e Canto da Mina (própria) as condições microbiológicas e físico-químicas daquelas fontes mostraram-se dentro dos padrões estabelecidos pela portaria 2914/11, representando assim potenciais fontes de abastecimento, merecedoras de atenção especial no que diz respeito a ações de conscientização e de preservação. Resultados semelhantes também foram observados por Ferreira (2012) em trabalhos desenvolvidos nas minas Canto da Mina e CSU.

Nos demais casos, CSU e mina do Baiano, necessita-se, além de adoção de alternativas de tratamento antes do consumo, de uma avaliação das causas que têm provocado a contaminação por coliformes termotolerantes, com vistas a torná-las também soluções alternativas de abastecimento de boa qualidade representando assim novas fontes, sobretudo em meio a uma crise de desabastecimento iminente.

Embora os índices pluviométricos da última estação chuvosa tenham ficado bem abaixo do esperado, as amostragens foram realizadas conforme previsto os resultados obtidos seguiram os mesmos padrões observados para o período seco, sem diferenças estatisticamente significativas. Neste contexto, torna-se especialmente importante a continuidade dos estudos e levantamentos locais a fim de se averiguar as condições que propiciaram condições adequadas de consumo em duas SACs, contrapondo-se às condições averiguadas nas outras duas SACs, e que não apresentaram resultados satisfatórios, tanto em sua condição microbiológica quanto em relação a aspectos físico-químicos.

Um dos desdobramentos do trabalho foi a criação de um Blog, denominado meioambientedivinopolis.blogspot.com, de natureza inédita na região, com informações e ilustrações referentes ao trabalho desenvolvido, servindo como meio de divulgação e disseminação das informações levantadas, dentre outras aplicações.

É fundamental que o monitoramento das condições das SACs utilizadas pela população local seja contínuo, tendo em vista as flutuações naturalmente observadas em virtude de variações sazonais de temperatura, pluviosidade e, principalmente, condições locais de cunho ambiental e até social, quando se verifica a presença de animais homeotérmicos, dejetos de animais, descarte de resíduos sólidos, contaminação ambiental diversa e até mesmo presença ou lançamento de esgoto doméstico onde o saneamento básico é precário ou inexistente. 


\section{CONCLUSÕES}

Não se recomenda a utilização de volumes de água provenientes das minas do Baiano e CSU para consumo próprio sem tratamento prévio, tendo em vista condições microbiológicas e físico-químicas que fogem aos parâmetros definidos em Lei. Sugere-se fervura por, no mínimo 5 minutos, a fim de se reduzir a carga bacteriana presente em amostras retiradas daquelas fontes hídricas. Em relação às minas Bela Vista e Canto da Mina (próprio), amostras de água delas provenientes apresentaram-se dentro dos padrões microbiológicos definidos em Lei representando, portanto, alternativas potenciais de novas fontes públicas de abastecimento para a população.

As quatro SACs estudadas foram devidamente georreferenciadas e os dados do trabalho encontramse disponíveis para livre acesso através do blog. Faz-se necessário o monitoramento e análises periódicas das condições microbiológicas e físico-químicas das fontes analisadas, tendo em vista questões relativas à sazonalidade propiciada pelas mudanças meteorológicas naturais ao longo do ano, sendo o trabalho considerado modelo para a execução de trabalhos de igual natureza em todas as minas do município. Estudos complementares são necessários a fim de se definir estratégias para a inversão das condições inapropriadas de duas das fontes analisadas e reforçar a necessidade de preservação da região limítrofe as fontes adequadas ao consumo.

\section{REFERÊNCIAS}

BECHARA, E. J. H.. O Homem e o Meio Ambiente. Química Nova, São Paulo, v.15, n.2, p.117, 1992.

BRASIL. Ministério da Saúde. Inspeção sanitária em abastecimento de água. Brasília: MS, 2006.

BRASIL. Ministério da Saúde. Portaria n.2914 de 12 de dezembro de 2011. Brasília: MS, 2011.

FERREIRA, B. A.. Verificação da qualidade da água de soluções alternativas coletivas (SAC's) para a realização de intervenções de promoção da saúde da população divinopolitana. Monografia (Bacharelado em Farmácia) Universidade Federal de São Joao Del-Rei, Divinópolis, 2012.

FUNASA. Fundação Nacional de Saúde. Manual Prático de Análise de Água. 3 ed. Brasília: FUNASA, 2009.

GOMES, C. L.. Biologia da água. Belo Horizonte: 1973.

GUILHERME, M. F. E.; OTTO, S. S.. Pseudomonas aeruginosa como indicador de contaminação hídrica. Higiene Alimentar, São Paulo, v.14, n.76, p.43-47, 2000.

IGAM. Instituto Mineiro de Gestão das Águas. Projeto Água de Minas: Relatório 2011. Belo Horizonte: IGAM, 2011.
LIMA, J. E. F. W.; FERREIRA, R. S. A.; CHRISTOFIDIS, D.. O uso da irrigação no Brasil. Brasília: MMA, 1999.

MCKINNFY, R. E.. Microbiology for Sanitary Engineers. New York: McGraw Hill, 1962.

MWH. Montgomery Watson Harza. Water treatment: principles and design. 2 ed. Hoboken: Wiley, 2005.

REBOUÇAS, A. C.; BRAGA, B.; TUNDISI, J. G.. Águas Doces no Brasil: capital ecológico, uso e conservação. São Paulo: 1999.

SAUNDERS, R. J.; WARFORD, J. J.. Abastecimento de Água em Pequenas Comunidades: aspectos econômicos e políticos nos países em desenvolvimento. Rio de Janeiro: ABES, 1983.

SPERLING, M. V.. Introdução à qualidade das águas e ao tratamento de esgotos. 3 ed. Belo Horizonte: UFMG, 2005.

TORTORA, G. J.; FUNKE, B. R.; CASE, L. C.. Microbiologia. 8 ed. Porto Alegre: Artmed, 2005.

WHO. World Health Organization. Inheriting the world: The Atlas of Children's health and the environment. Genebra: WHO, 2004.

A CBPC - Companhia Brasileira de Produção Científica (CNPJ: 11.221.422/0001-03) detém os direitos materiais desta publicação. Os direitos referem-se à publicação do trabalho em qualquer parte do mundo, incluindo os direitos às renovações, expansões e disseminações da contribuição, bem como outros direitos subsidiários. Todos os trabalhos publicados eletronicamente poderão posteriormente ser publicados em coletâneas impressas sob coordenação da Sustenere Publishing, da Companhia Brasileira de Produção Científica e seus parceiros autorizados. Os (as) autores (as) posteriormente ser publicados em coletâneas impressas sob coordenação da Sustenere Publishing, da Companhia Brasileira de Produção Científica e seus parce
preservam os direitos autorais, mas não têm permissão para a publicação da contribuição em outro meio, impresso ou digital, em português ou em tradução. 